\title{
AUTOMATIC DIPPER LIGHT CONTROL FOR VEHICLES
}

\author{
Tejas Vijay Narkar \\ B.E., Instrumentation Engineering, VPM's Maharshi Parshuram College of Engineering, Maharashtra, India
}

\begin{abstract}
Number of vehicles on our roads is increasing day by day, also the technology has developed but the safety factor is always needed to be considered. Now a day's vehicles come fitted with lots of safety features. One of the essential safety feature that need to be installed is automatic upper-dipper control of headlight, this feature can mainly use during night time driving. Human eyes are very sensitive to the light, if eyes suddenly comes in contact with the light after darkness, cornea present in eyes gets contract i.e. vision gets blank and require some time to recover the vision. Many times the situation comes when suddenly vehicle approaches from front with headlight in upper mode causes blindness to the eyes of the driver. During that time vehicle covers some amount of distance, here chances of accident may occur. It is a sheer luck if person goes safely through that situation. To overcome this manual dipping problem, an automatic mechanism has made to dip the headlight automatically whenever situation occurs. This can reduce number of accidents during night time and provide comfortable driving. Operating principle, working and design of PCB is briefly discussed in this paper.
\end{abstract}

Key Words: Automatic Control, Headlight, Upper, Dipper, etc...

\section{INTRODUCTION}

Now days the no. of vehicle on road is increasing drastically and no. of accidents on road also increases. Especially at night most of the accidents are occurred due to dazzling of headlight. While diving at night the headlight beam of oncoming vehicle is directly effects the driver's eye and eye gets blur, it takes 3 to $8 \mathrm{sec}$ to recover to its normal vision. Fig. 1 shows the high beam of headlight which causes blurriness on driver's eye. If at that time vehicle speed is $70 \mathrm{~km} / \mathrm{hr}$, causes the vehicle goes out of road or strikes on oncoming vehicle $[5]$.

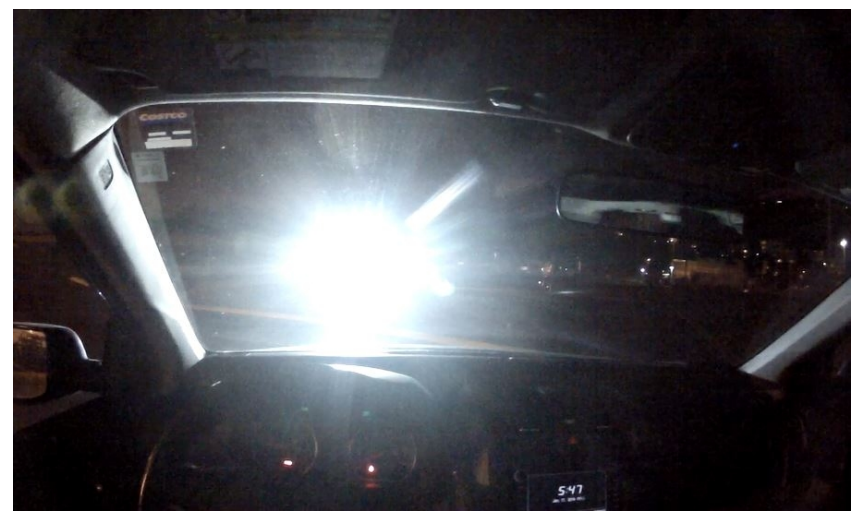

Fig-1: Headlamp at high beam intensity

In every vehicle dipper beam is provided in addition with the upper beam to reduce the dazzle from oncoming vehicle. Automatic dipper light control is a system which automatically changes the headlight from upper to dipper beam by sensing the headlight of oncoming vehicle ${ }_{[5]}$.

In the paper (ref.3), there is no arrangement for dipper connection as per circuit diagram they shown so the dipper beam cannot be able $\mathrm{ON}$ to and in the paper (ref.4) they demonstrate using LED's for upper and dipper beam, here no actual headlight beam is used [3][4]. To overcome these problems of both paper (ref.3 and ref.4), I design a new circuit which will directly operate the headlight beam. Some component must be added and changes in the wiring. In both the paper there is common problem is occur while driving in cities, street lights or lights of shops are affecting on the system and reduce the life of relay and headlamp. To reduce that, the manual mode which is already present in vehicle is used $_{[3][4] \text {. }}$.

\subsection{Problem Associated With Manual Dipping}

In current practice, to control dipper beam manually by using switch this is place on the steering column. Use of manual dipper control is not done by most of the drivers due to many reasons because the operation of dipper control switch is hundreds of times at night driving. Other reason is the driver wants to pay more attention to the steering control instead of to dipper the head light beam. Another major cause is 'ego problem', which makes each one wait till the other person initiates dipping, which may not happen ${ }_{[5]}$.

\section{HEADLIGHT OF VEHICLE}

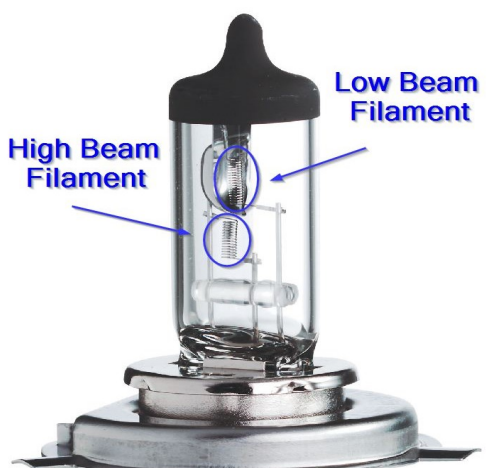

Fig-2: Double filament headlamp 
The headlight vehicle is fitted with double filament bulb shown in fig.2. Here one filament is used for upper beam and another for dipper beam. While driving at night, the headlight is the only source of vision and it require essentially from evening 6.00pm to morning 6.00am. Driver can switch the headlight from upper beam to dipper beam or vice versa using manual switch ${ }_{[4]}$.

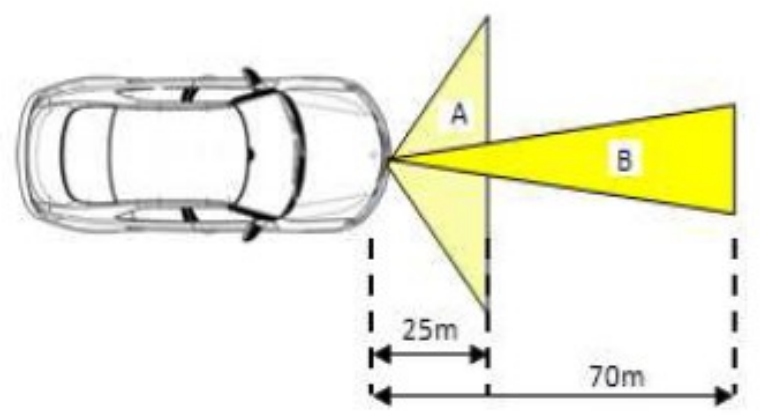

Fig-3: Range of dipper beam (A) and upper beam (B) of a vehicle

Upper beam covers the larger distance up to $70 \mathrm{~m}$ and dipper beam covers the small distance up to $25 \mathrm{~m}$ and at both the time intensity of head light is different. Fig. 3 gives the clear idea about how much distance covered by headlight for upper beam and dipper beam ${ }_{[4]}$.

\section{CIRCUIT DEVELOPMENT}

\subsection{PCB Design}

PCB design for this system is not so critical because it contains less no. of circuit components. Here dotted PCB is used to implement the circuit as per the circuit diagram. Easily available and most accurate component are used for design, implementation of components shown in fig. 4 .

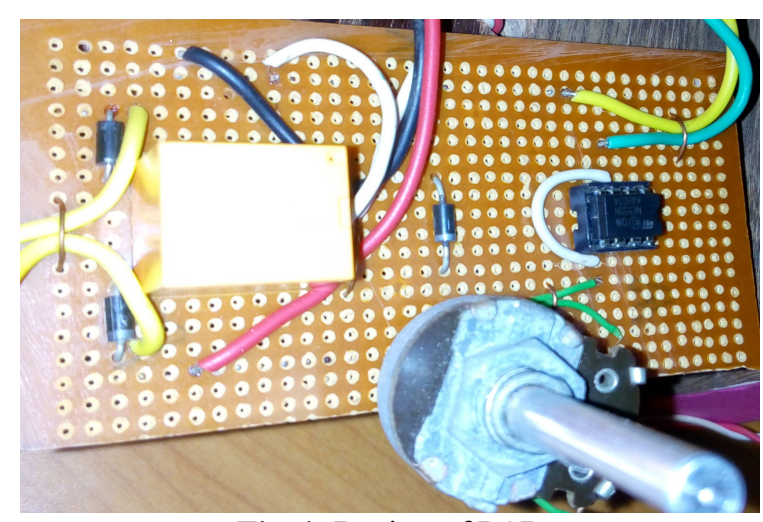

Fig-4: Design of PCB

\subsection{Circuit Components}

\subsubsection{IC 555}

The 555 timer IC is the main control of this system and it is mainly known for generating stable time delays. Here for this system, monostable mode is used for developing the timing logic. It is an 8 pin IC available in dual-in-package (DIP). Fig. 5 shows the pin diagram of $555 \mathrm{IC}_{[7]}$.

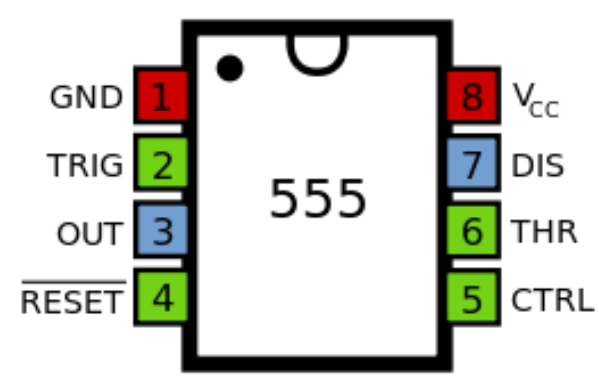

Fig-5: Pin diagram of IC 555

\subsubsection{LDR}

In this system LDR is act as sensor to sense the headlight beam of oncoming vehicle. Fig. 6 shows the constructional diagram of LDR.

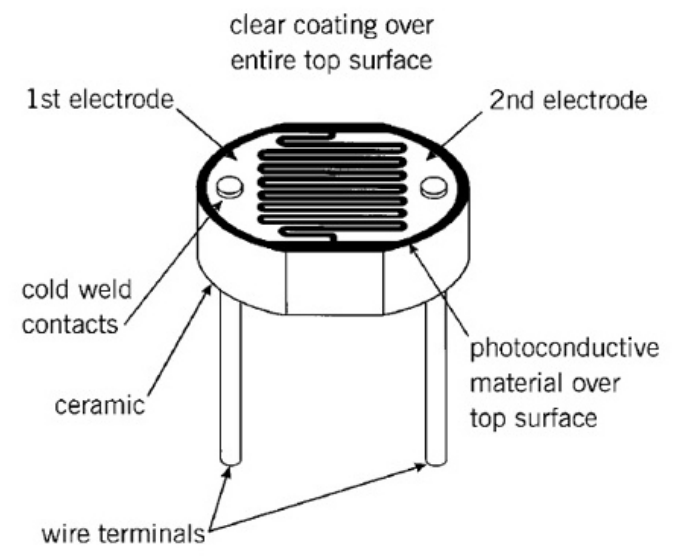

Fig-6: Construction of LDR

LDR is a light dependent resistor, the resistance of LDR increases in dark up to $20 \mathrm{k} \Omega$ and decreases up to few hundred $\Omega$ in light ${ }_{[10]}$.

\subsubsection{Relay}

In this system relay is used as switch to change the lamp connections from upper beam to dipper beam. Relay is electromagnetic switch which operates when current is flowing through its coil. Connection of upper beam is given to $\mathrm{NC}$ (normally close) terminal; dipper beam is given to NO (normally open) terminal and common is connected directly connected to $12 \mathrm{~V}$ supply [9].

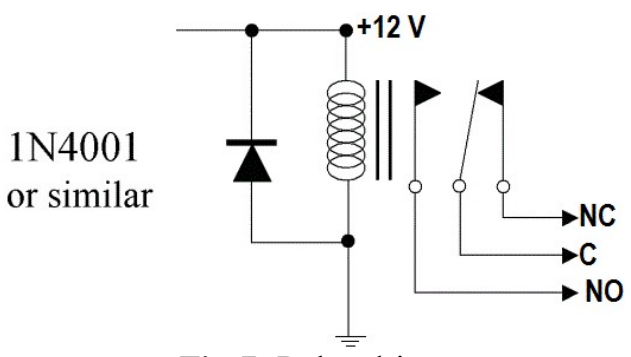

Fig-7: Relay driver

Fig.7 shows the relay driver circuit. Relay coil is energized when output of 555 IC gets high and vice versa. 


\subsubsection{Switches}

Switch is generally used for to make or to break the contact; here two SPDT (Single Pole Double Through) switches are used, one for selecting the automatic or manual dipper control mode and other for manual upper-dipper of headlight. Fig.8 shows the construction of SPDT switch [9].

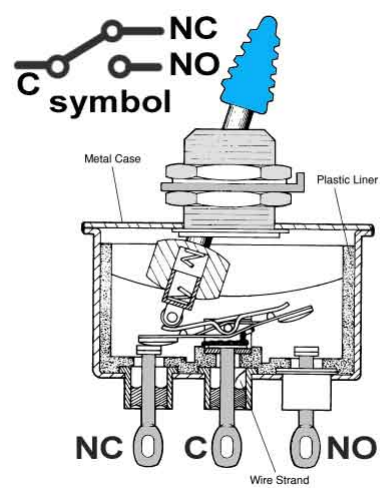

Fig-8: Construction of SPDT switch

\subsubsection{Diodes and Potentiometer}

While using manual mode there is possibility of flowing reverse current through circuit and relay driver always needs a diode for blocking reverse current. In this system three diodes were use mainly for blocking the reverse current flow through the circuit because diode can operate only in one direction (forward bias) and block all current in reverse direction (reverse bias). Potentiometer of $10 \mathrm{~K}$ is used for adjusting intensity as well as to control time period 555 IC.

\subsubsection{Battery Source}

This system uses $12 \mathrm{~V}$ supply which is directly taken from vehicle battery, already present in each vehicle. It provides constant DC supply and the system is safely operated on vehicle battery supply and does not require any external components.

\section{OPERATING PRINCIPLE AND WORKING}

\subsection{Operating Principle}

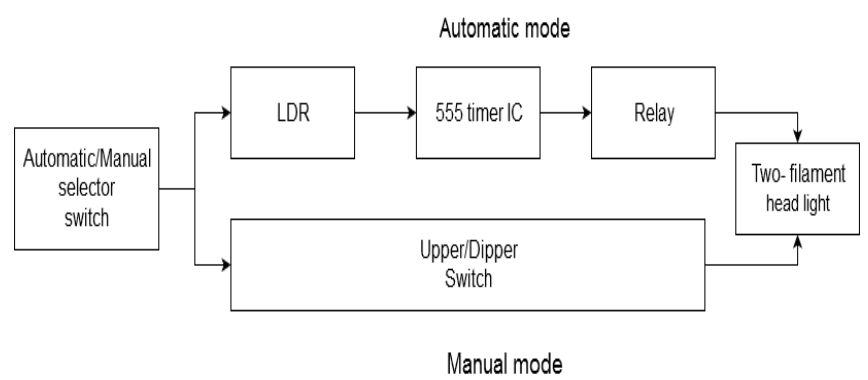

Fig-9: Block diagram of dipper control

From the block diagram shown in fig.9 it gives the clear idea about dipper control system. In automatic mode LDR senses the headlight of approaching vehicle, as the resistance of LDR changes as per light intensity. Due to change in intensity the voltage given to 555 timer control IC becomes high or low. On the basis of trigger and threshold condition, the output changes its state to high or low according to that the relay coil will energize or de-energize. Relay change its position from NC to NO it will cause the headlight control from upper to dipper. Once the approaching vehicle passed away, LDR goes in dark and output of 555 IC change. It changes headlight beam from dipper to upper ${ }_{[1][2] \text {. }}$

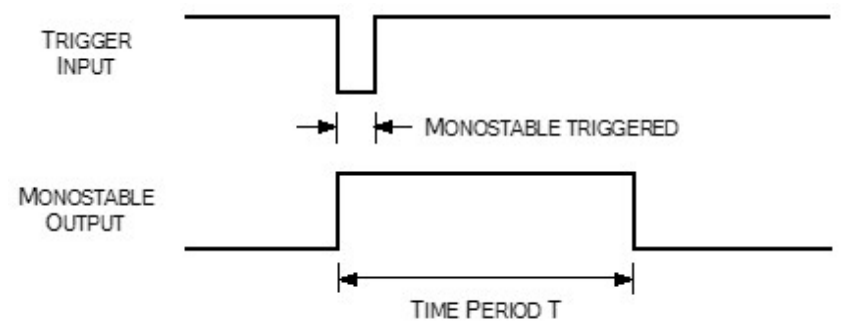

Fig-10: Waveform of IC 555 in monostable mode

This system uses the monostable mode of 555 timer application. Fig.10 shows the output waveform of monostable mode which gives the time delay $\mathrm{T}$ after low input pulse applied to $555 \mathrm{IC}_{[5]}$.

\subsection{Working}

Basically, there are two modes of working viz. manual and automatic mode, for selecting manual and automatic mode SPDT switch $\left(\mathrm{S}_{1}\right)$ is provided. In manual mode for the general practices use the SPDT switch $\left(\mathrm{S}_{2}\right)$ for controlling upper and dipper condition of the headlight. In manual mode avoidance of flowing reverse current through automatic system, diode $\mathrm{D}_{2}$ and $\mathrm{D}_{3}$ are connected to $\mathrm{NC}$ and $\mathrm{NO}$ terminal, it only operates in forward direction it means only for automatic mode.

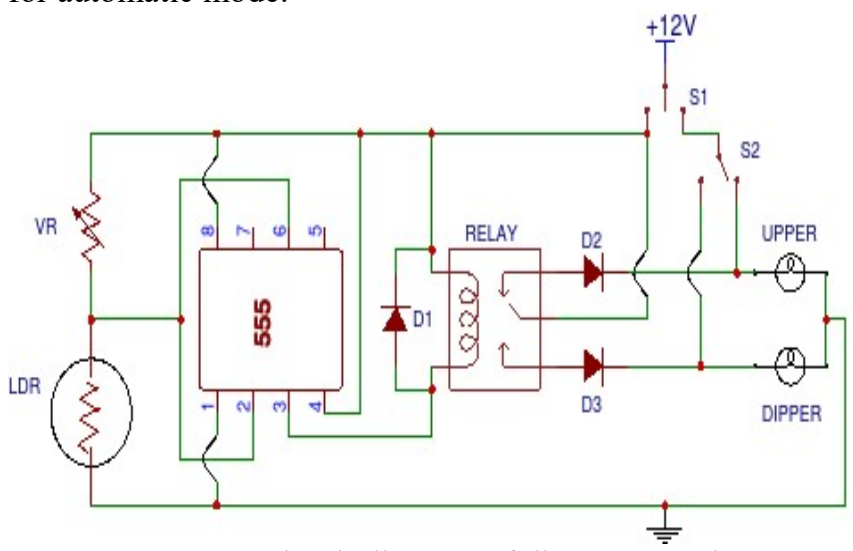

Fig-11: Circuit diagram of dipper control

Automatic mode is consisting of light dependent resistor (LDR), 555 IC, relay and few other components as shown in fig.11. Normally, LDR's resistance is high $(20 \mathrm{k} \Omega)$ in darkness and low $(2 \mathrm{k} \Omega)$ in brightness. VR and LDR work as the potential divider and VR is used to control output voltage of potential divider which causes change in controlling time period and intensity of LDR.

Fig. 12 shows the internal structure of 555 IC, in that three resistors of $5 \mathrm{k} \Omega$ act as voltage divider and gives the voltage 
$2 / 3 \mathrm{~V}_{\mathrm{cc}}$ to comparator 1 and $1 / 3 \mathrm{~V}_{\mathrm{cc}}$ to comparator 2 , where $\mathrm{V}_{\mathrm{cc}}$ is the supply of $12 \mathrm{~V}$. These two voltages give the timing interval $[6]$.

When light of approaching vehicle falls on LDR the resistance of LDR get decrease to $2 \mathrm{k} \Omega$ and voltage which is directly given to threshold and trigger pin gets shorted to ground.

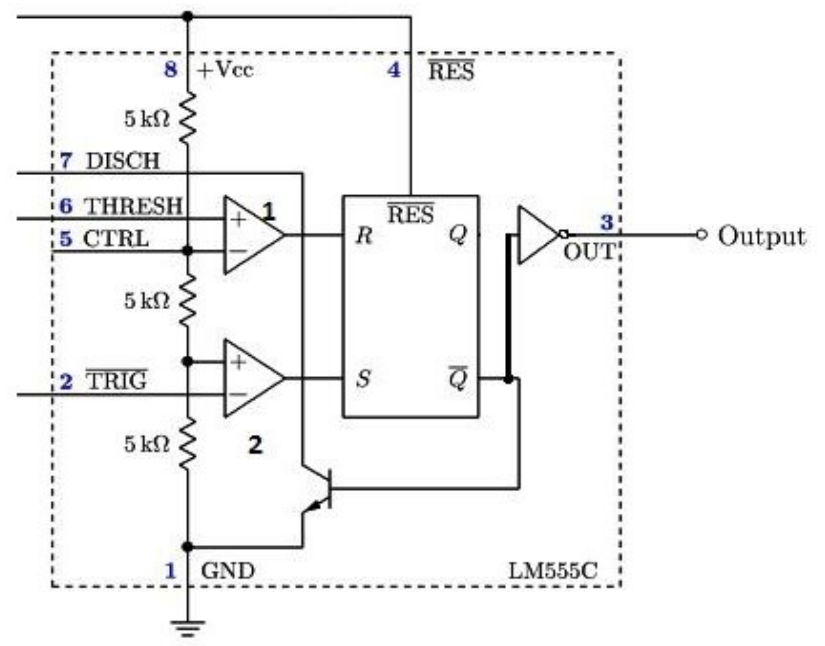

Fig-12: Internal Structure 555 IC

Due to that a negative voltage is going to trigger pin, which is set at $1 / 3 \mathrm{~V}_{\mathrm{cc}}$ by comparator 2 . If that voltage is equal to $1 / 3$ $\mathrm{V}_{\mathrm{cc}}$, the comparator 2 output goes high and comparator 1 is not equal to $2 / 3 \mathrm{~V}_{\text {cc }}$ so its output is low. It sets $\mathrm{FF}$ at $\mathrm{S}=1, \mathrm{R}=0$ and output of $\mathrm{FF}$ is $\mathrm{Q}=1, \overline{\mathrm{Q}}=0$, this output is inverted by inverter present at pin 3 hence output of 555 IC becomes high. Relay coil gets energized and changes its connections from upper (connected to NC) to dipper (connected to NO). This condition is present till the light continuously falls on LDR means approaching vehicle light beam still falls on LDR sensor.

Once the approaching vehicle is passed away, LDR sensor goes in darkness. The resistance of LDR get increases to 20 $\mathrm{k} \Omega$ and voltage which is get shorted due to low resistance of LDR, is recovered and given to threshold and trigger pins of 555 IC.

Due to that the positive voltage is going to threshold pin which is set at $2 / 3 \mathrm{~V}_{\mathrm{cc}}$ by comparator 1 . If that voltage is equal to $2 / 3 \mathrm{~V}_{\mathrm{cc}}$ the comparator 1 output goes high and comparator 2 is not equal to $1 / 3 \mathrm{~V}_{\mathrm{cc}}$ so output is low. It sets $\mathrm{FF}$ at $\mathrm{S}=0, \mathrm{R}=1$ and output of $\mathrm{FF}$ is $\mathrm{Q}=0, \overline{\mathrm{Q}}=1$, this output is inverted by inverter present at pin 3 hence the output of 555 IC becomes low. Relay coil will be de-energized and changes its connection from dipper (connected to NC), this condition is present till any light beam of approaching vehicle falls on LDR sensor.

\section{EXPERIMENTATION AND RESULT}

The circuit is built according to circuit diagram on the breadboard and $12 \mathrm{~V}$ power supply is applied to the circuit.
Adjust the $10 \mathrm{k} \Omega$ potentiometer (VR) for adjusting the light intensity with surrounding intensity to energize relay. LDR's resistance is high $(20 \mathrm{k} \Omega)$ in dark and low $(2 \mathrm{k} \Omega)$ in light. Allow the small torch light to be fall on the LDR, measure the resistance of LDR and operating range of relay. With the help of small torch, we vary the resistance of the LDR and we measure some distance at different resistance were relay can operate successfully. Following chart 1 will give exact idea about that-

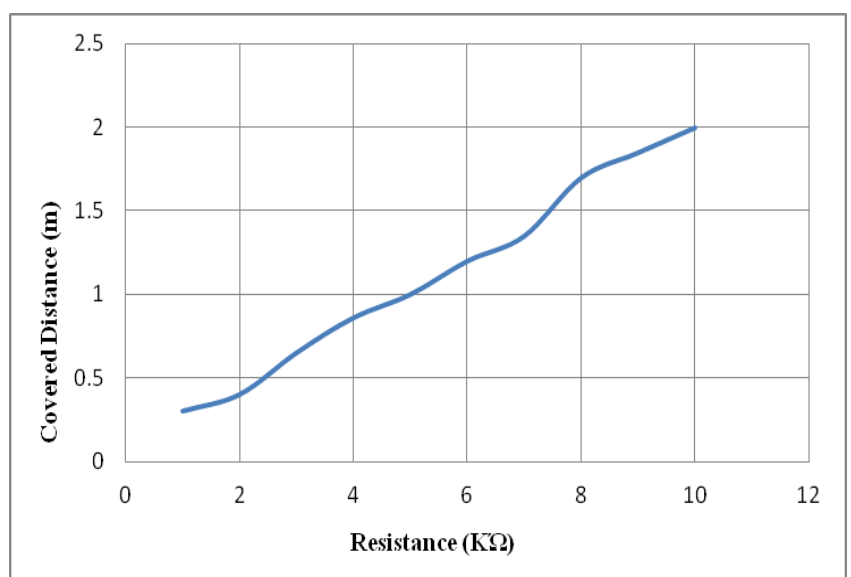

Chart-1: Graph of Resistance v/s Covered distance

Hence the above graph indicates that in darkness the LDR resistance is high and in light the resistance is low. Therefore we adjust potentiometer (VR) at $10 \mathrm{k} \Omega$ in the circuit, because at night darkness is more and light intensity of vehicles coming from front is high. So the dipper control is depending on light intensity and distance.

\section{CONCLUSIONS}

Automatic dipper provides better safety at night time and drivers can drive comfortably and reach their destination safely. There are two modes provided viz. automatic and manual mode. While driving in the cities there are light everywhere which can affect the working of the device at that time the mode can shift to manual mode to avoid flickering of the headlight. When both the vehicles were fitted with the "Automatic Dipper" then both the vehicles dip the headlight beam of each other efficiently. Main components helps to run the circuit are easily available and are also cheap. The circuit is compatible with any vehicle and doesn't require any other supply; it can efficiently work on battery fitted in the vehicles. Therefore the installation of this safety system in each vehicle give safety at night driving, increase comfort level of driver and decrease the road accidents.

\section{ACKNOWLEDGEMENT}

I thankful to Dr. Shekhar Gadgil for giving me guidelines to develop the project which is very important in India, also grateful to my HOD Prof. Avinash Pawar for providing me the required guidelines and material for development of project. 


\section{REFERENCES}

[1] Ramakant Gayakwad, "Op-Amps \& Linear Integrated Circuits", $4^{\text {th }}$ ed. PHI Learning Private Limited, New Delhi, pp. 400-405.

[2] D. Roy Choudhary, "Linear Integrated Circuits", $4^{\text {th }}$ ed. New Age International Publishers, pp. 311-315.

[3] Sushil Kumar Choudhary, "Electronic Head Lamp Glare Management System for Automobile Applications", International Journal of Research in Advent Technology, Vol.2, No.5, May 2014, pp. 402416.

[4] Muralikrishnan.R, "Automatic Headlight Dimmer A Prototype for Vehicles", International Journal of Research in Engineering and Technology, Vol.3, Issue: 02, Feb-2014, pp. 85-90.

[5] www.autodipper.com/concept.html/

[6] www.circuitstoday.com/555-timer/

[7] http://en.wikipedia.org/wiki/555_timer_IC/

[8] www.electronicsproject.org/automatic-dipper-forvechical/

[9] https://learn.sparkfun.com/tutorials/switchbasics/polesand-throws-open-and-closed

[10] https://en.wikipedia.org/wiki/Photoresistor

\section{BIOGRAPHIES}

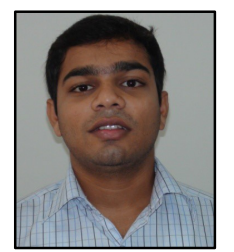

Tejas Vijay Narkar was born in Mumbai, India on 13.03 .1993 and completed his schooling from Technical Highschool in the Year 2009. After that completed Diploma in Industrial Electronics Engineering and currently pursuing the under-graduate course, B.E. (Instrumentation Engineering) in Maharshi Parshuram College Of Engineering, Maharashtra, India. His areas of interests include Industrial Automation, Robotics, Sensors and Transducers. 